\title{
Assessment of traffic-induced vibrations of Ozanam Building of Adamson University
}

\author{
Earl Shadd D. Araña, Leira Liz A. Bisain, Rae Cecil N. Acedera, John Elmer C. Guillermo and \\ Albert A. Griño, Jr. ${ }^{a}$ \\ Civil Engineering Department, Adamson University, Philippines
}

\begin{abstract}
Vibration is one of the main factors for fatigue in structures which can cause damages such as cracks and in critical cases could result to collapse. Long term contact to vibrations can induce the cracks to be transmitted through the structural members of the building that can compromise the structural integrity of the structure. The Ozanam Building of Adamson University is situated near the Romualdez Street, which is considered as one of the main routes of cargo trucks and other heavy vehicles from the Manila North Harbor Port. It was observed that cracks were visible on the façade of the building. For that reason, the structural integrity of Ozanam Building was evaluated against the traffic-induced vibrations using vibration meter. It was found out that the maximum peak particle velocity present in Ozanam Building is $8.60 \mathrm{~mm} / \mathrm{s}$ which means that the building is safe and below the threshold value for risk in structural damage. Thus, vibration due to traffic has no significant effect that can cause structural damage to the building. In addition, preventive measures were discussed in this paper to reduce the traffic-induced vibrations to an acceptable level.
\end{abstract}

\section{Introduction}

\subsection{Background of the study}

Vibration is one of the main factors for fatigue in structures. Produced by different sources, vibrations propagate from one medium to the other. Long-term contact to vibrations can cause damages in buildings, minor effects such as cracks, which in critical cases could result in collapse. Also, these vibrations can cause errors to laboratory experimentation which are operating in Micro and Nano Scales.

According to Hajek [1], it is usual for large transportation agencies to receive complaints from residents living near highways about annoying highway noise. Complaints about vibration caused by highway traffic are less frequent, but they do occur. Typically, vibration complaints are also accompanied by complaints about excessive highway noise. Many transportation agencies do not have applicable guidelines for the resolution of vibration complains.

The vibrations can be measured by using a vibration meter that usually measures the peak particle velocity. This instrument can also be used to know the amplitude and frequency range of vibrations.

\footnotetext{
${ }^{a}$ Corresponding author : aagrino@gmail.com

(C) The Authors, published by EDP Sciences. This is an open access article distributed under the terms of the Creative Commons Attribution License 4.0 (http://creativecommons.org/licenses/by/4.0/).
} 
The peak particle velocity is the maximum speed of a particle as it oscillates about a point of equilibrium that was moved by a passing wave.

According to Hunaidi [2], like most vibration problems, traffic vibrations can be characterized by source-path-receiver scenario, which is shown in the Figure 1.Vehicle contact with irregularities in the road surface (i.e. potholes, cracks and uneven manhole covers) induces dynamic loads on the pavement. These loads generate stress waves, which propagates in the soil, eventually reaching the foundations of adjacent buildings and causing them to vibrate. Heavy vehicles such as buses and trucks mainly cause traffic vibrations. Passenger cars and light trucks rarely induce vibrations that are perceptible in buildings.

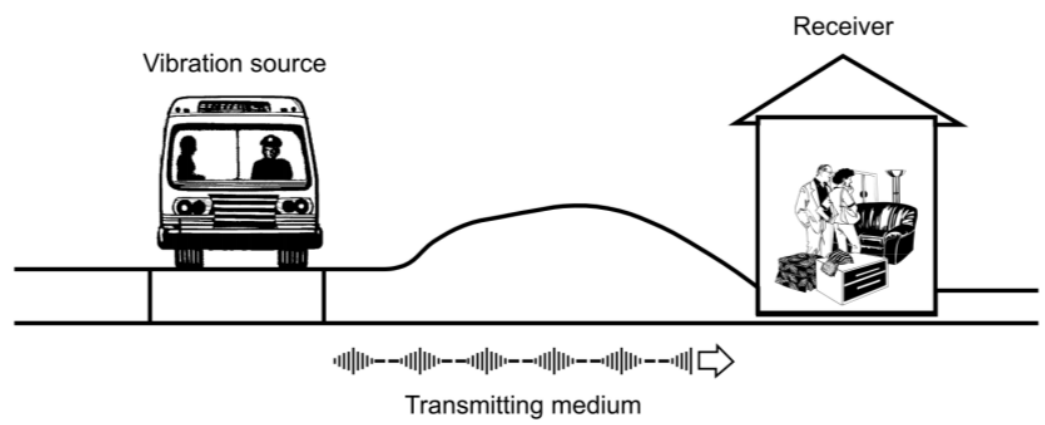

Figure 1. Traffic vibrations in source-path-receiver scenario (Hunaidi, 2007)

On a study presented by Hajek [1], the condition of the pavement surface is the decisive contributor to ground-borne vibration. It is also the most significant factor that can be controlled by highway agencies. Discrete pavement discontinuities, such as stepped transverse cracks exceeding about $4 \mathrm{~mm}$, appear to be significant enough to overshadow the effect of random surface roughness and result in specific sources of vibration. Heavy vehicles produce higher ground-borne vibration because of the larger mass acting on the pavement, and typically higher sound levels. Trucks equipped with steel suspension can produce higher dynamic loads and vibrations compared to trucks equipped with air suspension.

The Ozanam Building of Adamson University houses the College of Engineering and its departments. The said building is continuously experiencing vibrations due to the flow of cargo trucks and traffic. These trucks are going and coming from the Pier located at Manila, carrying imported and exported goods.

Thus, the researchers partook on a study of the evaluation of the traffic-induced vibrations in Ozanam Building in Adamson University.

\subsection{Objectives of the study}

\subsubsection{General objective}

The objective of this study is to evaluate the traffic-induced vibrations occurring on the Ozanam Building of Adamson University.

\subsubsection{Specific objectives}

1. To determine the peak hour in which vehicles that cause traffic-induced vibrations pass through the Romualdez Street.

2. To determine the peak particle velocity and the effects of the vibration to the Ozanam Building in reference to the Transport and Road Research Laboratory (U.K.) and the British Standards Institute; 
3. To determine the location in the Ozanam Building that experiences the greatest intensity of vibrations using the vibration meter and total station; and

4. To determine if there are any visible damages on the building that is due to the vibrations induced by the traffic at Romualdez Street.

\subsection{Significance of the study}

This study is helpful in improving the structural facilities of the Ozanam Building of Adamson University. This also ensures the safety of the students occupying the building. Most occupants of the OZ Building are engineering students. They are taught that safety, welfare and public interest of the people is the paramount priority of the designers and thus, this study ensures their safety.

This study also helps the quality of the life of the socially disadvantaged because of the knowledge that this paper contributes to the civil engineering community. It might lead to advancements that ensures the protection of the occupants of buildings against traffic-induced vibrations.

Not only does the Adamson University community benefit from this study, but also all buildings within the vicinity of Adamson University and Romualdez Street. This study helps structural designers and contractors build structures, which can withstand vibrations and other seismic events. This research also contributes knowledge on future studies since that assessment of buildings integrity is considered uncommon like any other studies.

\section{Review of related literature}

\subsection{Peak particle velocity}

The peak particle has been established as the best measure of the damage of potential of ground vibrations. The US Bureau of Mines [3] originally suggested a limit of $50 \mathrm{~mm} / \mathrm{s}$ as being safe for residences but in fact the problems occur below this level and Hajek now suggest $12.5 \mathrm{~mm} / \mathrm{s}$ as a safe limit for older properties.

The Ozanam is considered as an old property since it has been constructed for a long time. Therefore, any peak particle velocity reading from the vibration meter that is greater than $12.5 \mathrm{~mm} / \mathrm{s}$ should be understood that the Ozanam Building is in the risk of potential damages.

\subsection{Assessment of ground-borne vibrations}

According to Hunaidi and Tremblay [4], the process of assessing a potential ground-borne vibration problem consists of establishing vibration levels at the receiver and comparing them with acceptance criteria. The study found out that highway traffic induced ground-borne vibration can be perceptible in very extreme circumstances. However, typically, the feeling of vibration reported by residents living near highways is due to low frequency sound levels produced by trucks that can cause resonance of light exterior or interior building and room elements. Ground-borne vibration induced by highway traffic can be effectively controlled by the maintenance of smooth roadway surfaces [1]. Also, the study shows a graph about the relationship between the vibrations of the establishment compared to the distance from the center line of the lane.

As seen in Figure 2 that the Peak Vertical Particle Velocity decreases exponentially with distance from the centerline of the lane as well as the acceptable threshold value for perception, historical building and architectural damages. 


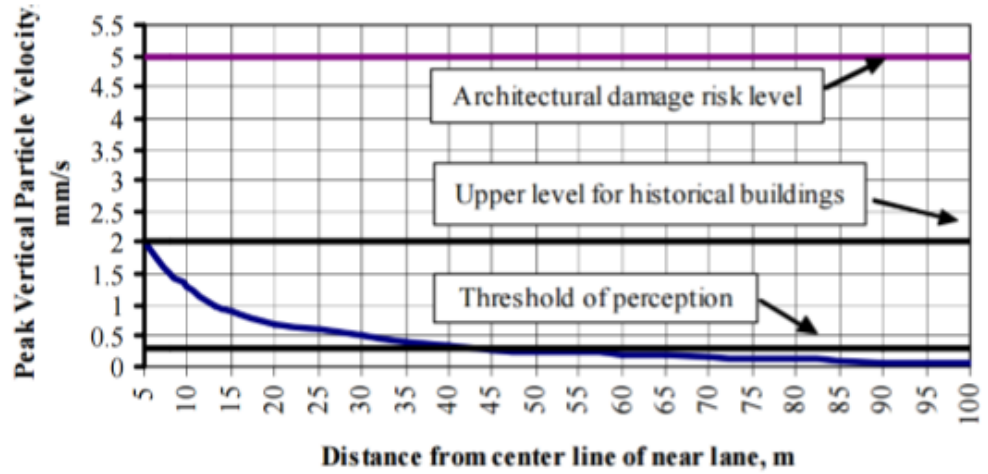

Figure 2. Maximum highway truck vibration level versus distance (Hajek, 2006)

\subsection{Transport and road research laboratory in United Kingdom}

The researchers from the Transport and Road Research Laboratory (TRRL) in United Kingdom carried out an extensive work about traffic induced vibrations and they developed a guidelines for assessing vibrations caused by traffic. Whiffin and Leonard [5] proposed the guidelines as shown in Table 1 to assess the effects of vibration on people and buildings.

Table 1. Effects of Vibration on People and Buildings (Whiffin and Leonard, 1971)

\begin{tabular}{|c|c|c|}
\hline $\begin{array}{c}\text { Peak Particle Velocity } \\
\text { (mm/s) }\end{array}$ & Human Reaction & Effects on Buildings \\
\hline 0 to 0.15 & Imperceptible & Unlikely to cause damage of any type \\
\hline 0.15 to 0.30 & Threshold of Perception & Unlikely to cause damage of any type \\
\hline 2.0 & Vibrations Perceptible & $\begin{array}{c}\text { Effects ancient and historical } \\
\text { monuments }\end{array}$ \\
\hline 2.5 & $\begin{array}{c}\text { Continuous exposure to vibration is } \\
\text { annoying }\end{array}$ & $\begin{array}{c}\text { Virtually no risk of architectural } \\
\text { damage to normal buildings }\end{array}$ \\
\hline 5.0 & $\begin{array}{c}\text { Vibrations annoying to people in the } \\
\text { buildings }\end{array}$ & $\begin{array}{c}\text { Threshold for risk of architectural } \\
\text { damage in house with plastered walls } \\
\text { and ceilings }\end{array}$ \\
\hline 10 to 15 & $\begin{array}{c}\text { Continuous vibrations are unpleasant and } \\
\text { unacceptable }\end{array}$ & $\begin{array}{c}\text { Would cause architectural damage and } \\
\text { possibly minor structural damage }\end{array}$ \\
\hline
\end{tabular}

\subsection{Damages to structures due to traffic-induced vibrations}

According to Hunaidi [6], house owners may complain about damage induced by traffic vibrations, such as cracks in walls and ceilings, separation of masonry blocks, and cracks in foundation. However, vibration levels are rarely high enough to be the direct cause of this damage, though they could contribute to the process of deterioration from other causes. Building components usually have residual strains as a result of uneven soil movement, moisture and temperature cycles, poor maintenance or past renovations and repairs. Therefore, small vibration levels induced by traffic could trigger damage by "topping up" residual strains. Consequently, it is difficult to establish a vibration level that may cause building damage and, therefore, controversy continues to surround the issue. In some cases, when a building is subject to vibration for many years, fatigue damage (i.e. that caused by repeated loading) may occur if the induced stresses in the building are high enough. In addition to damage caused directly by vibration, indirect damage may result from differential movements caused by soil settlement due to densification. Loose sandy soils are particularly susceptible to densification when subjected to vibration. 
Several countries have adopted standards for evaluating the effect of vibration on buildings. No such national standards exist here in the Philippines. The most stringent vibration guide value specified in published standards for damage to house is more than 30 times the human perception level. Occupants would therefore find potentially damaging vibrations to be extremely annoying because of their very high level.

According to Hunaidi [7], solutions and preventive strategies that have been suggested to reduce vibration to an acceptable level include periodic maintenance of road surfaces, control of traffic flow and speed, improvement of the road structure, sufficient distance between roads and buildings, building isolation systems and screening of vibration using in-ground barriers. Some of these measures have proven to be effective. However, there is no easy way to completely remove the vibration due to traffic.

According to Mathur [8], there are no easy ways to mitigate traffic vibrations. There are, however, a limited number of options available to reduce vibration to an acceptable level include soil improvement, reduction of road traffic-induced vibrations by layered soil bags, geofoam trench method, tuned mass damper and fluid vicious dampers.

The researchers use these guidelines in formulating a recommendation on how to prevent damages to the Ozanam Building or to reduce the vibration to an acceptable level.

\section{Methodology}

\subsection{Data collection}

According to Jaswal [9], collection of data would require building wave barriers to isolate vibration sources by digging trenches around the building boundary. Wave barriers are expensive to build and takes a lot of space for implication thus it is not viable in urban areas. The researchers followed the said principle considering that most of the students occupy the Ozanam Building and would rarely be unoccupied.

The researchers determined the Peak Hour on which the vehicles caused traffic-induced vibrations. This determined the time on which the researchers conducted the vibration meter reading. Safety concerns were always present when personnel are working near or adjacent to a highway. Safety considerations included the workers as well as the motoring public. Construction safety has received extensive attention, but this research focused on personnel working near or adjacent to the highway, which were involved in conducting the activities such as: collecting data, setting up data collection equipment or administrating roadside interviews.

The observers positioned clearly in order to see the traffic they were counting. Trucks, buses, parked cars or signs, which typically blocked vantage points, were avoided. They were located away from the traveled way for safety of the counter as well as affecting the drivers. The observer wore safety vest every time it gets near traffic. Seated at a parked car, provided protection from the elements and provided safety for the observer; however, it was located in such a way that it did not interfere with the typical traffic movements. A sign indicated that traffic counting was in progress satisfied most driver's curiosity, which avoided unwanted interruptions.

As with any field collection of traffic data, care was considered in protecting the observer at all times. The researchers wore reflective vests, and acted in a manner that does not distract motorists or influence their driving behavior.

\subsubsection{Determination of peak hour}

The researchers determined the time on which the data needed in this study were being collected. The researchers allotted two (2) days in determining the peak hour factor. The Peak Hour Factor (PHF) measured the relationship between the peak 15-minute interval of traffic compared to the total vehicle 
volume over the entire Peak Hour. It represented how constant vehicle volumes were, during the peak hour. The PHF is a ratio of the total hourly traffic volume against the busiest 15-minute interval.

The researchers tallied-in the number of vehicles that were travelling at high-speeds and the vehicles that yielded vibrations. In guaranteeing, the researchers conducted the procedure in the Ozanam Carpark, which is a safe place and is more effective due to the proximity to the Romualdez Street.

The researchers used statistical methods such as mean and standard deviation on the determination of peak hour due to multiple numbers of trials and observations. The mean for every time interval was used in the computation of the PHF.

The following formulas were used in this analysis:

$$
\begin{gathered}
\text { MEAN }=\bar{x}=\left(\sum_{i=0}^{n} x_{i}\right) / n \\
\text { STANDARD DEVIATION }=\sigma=\sqrt{\sum_{i=0}^{n} \frac{\left(x_{i}-\bar{x}\right)^{2}}{n-1}} \\
P H F=\frac{V}{4 x V p}
\end{gathered}
$$

Where: $x_{i}=$ vehicle count per time interval

$n=$ number of trials

$V_{p}=$ Peak 15-minute Volume

$V=$ Peak Hourly Volume

$\mathrm{PHF}=$ Peak Hour Factor

\subsubsection{Set-up of the vibration meter}

For proper evaluation of the effect of building vibrations induced by road traffic, measured vibrations were undistorted together with data processing and analysis that followed in the established procedures. Instrumentation for the measurement of vibration signals as shown in Figure 3, which includes vibration sensors, signal conditioners, and recording equipment, had sufficient resolution and sensitivity. Measurements were gathered at locations where the vibration levels reflect the purpose of the evaluation. In evaluating the effect of vibrations with respect to human annoyance, measurements were taken at locations where the vibration level found out greatest, normally at the midpoints of floors. On wood floors, the measurement points were located near joists to avoid local resonance of individual floor panels.

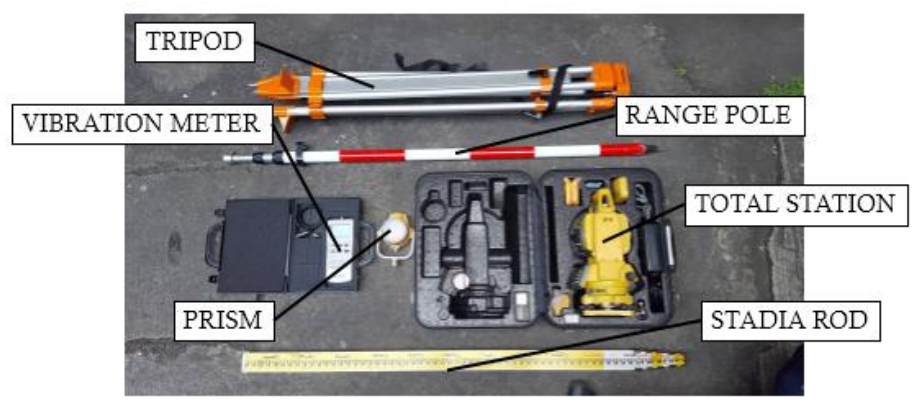

Figure 3. Equipments and Apparatus used for data collection. 
The researchers collected data in the corners of the Ozanam Building. The Lutron Vibration Meter's vibration sensor was mounted on the walls of the points of data collection. The points of data collection where chosen because the researchers took in the priority to evaluate the structural integrity of the Ozanam building. The gathering of data using the vibration meter lasted for at least a quarter of an hour within the peak hour.

After computation of the latitudes and departures, the researchers plot the coordinates in a plane and connect the columns from one another in order to determine the dimensions of the Ozanam Building. This shall now be added to the dimension of the setback and the sidewalk.

\subsection{Data analysis}

In evaluating the effect of vibrations on a building, measurements were made on the foundation and on the ground close to the building on the side facing the road. Vibration sensors were mounted using methods that can faithfully transmit to the transducer- the actual motion of the ground or building components over the frequency range of interest. Since the mounting method was not suspected of distorting the motion, therefore alternative methods were not tested.

The degree of detail required in the analysis of the vibration signals depends on the nature and purpose of the investigation. For a preliminary evaluation, it might be sufficient to find the peak of the vibration signal and to determine the predominant frequency of vibration by counting the number of negative and positive peaks in a given time interval. For an in-depth evaluation, advanced analysis methods are necessary, such as one-third-octave frequency band analysis, frequency-weighting according to established human response curves, and spectral analysis.

This study was considered a preliminary investigation because it was the first study of its kind that was conducted on the Adamson University. As written in the related literature of this paper, the researchers focused on the determination of the Peak Particle Velocity because of the functionality of the vibration meter and in order to avoid further complications.

The data collected was plotted in a graph showing the relationship between the Peak Particle Velocity (PPV) and the distance from the Romualdez Street.

\section{Results and discussion}

\subsection{Peak hour analysis}

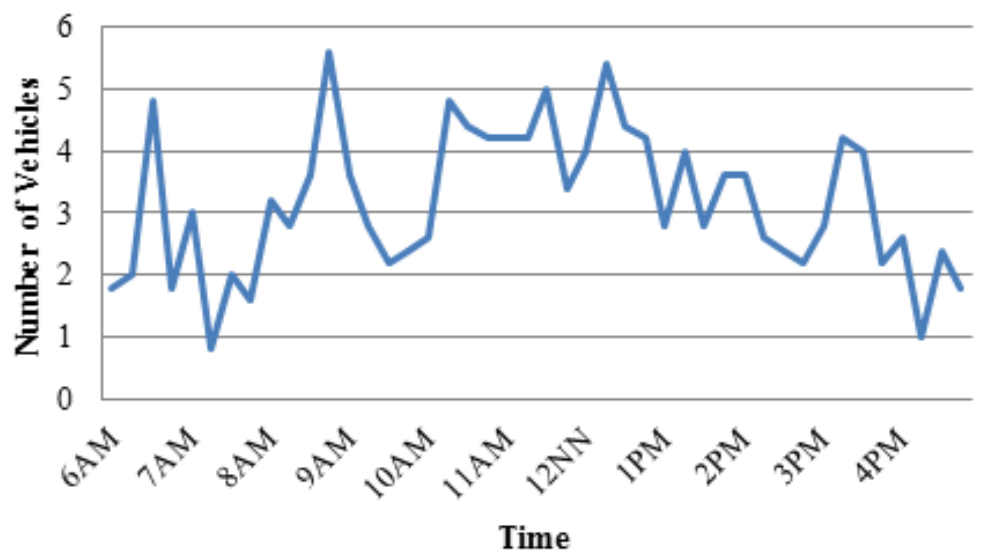

Figure 4. Variation of the number of vehicles traversing Romualdez St. from 6 AM to 5 PM 
As shown in Figure 4, the variation of the number of heavy vehicles traversing Romualdez St with respect to time. The data obtained from this figure is important in order to compute and generate a graph for the peak hour factor as shown in Figure 5. The peak hour analysis showed that the ideal time interval to conduct the study is from 11:00 AM to 12:00 NN with a peak hour factor of 0.96. This value is close to one which means that the traffic volume at that particular time interval is almost constant.

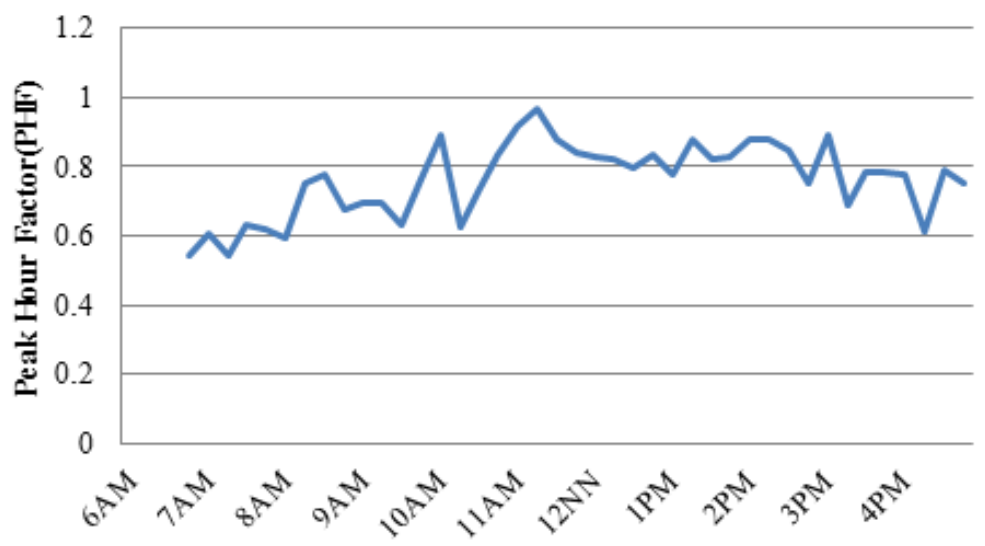

Time

Figure 5. Variation of the Peak Hour Factor (PHF) from 6 AM to 5 PM

\subsection{Distances of the columns of Ozanam building to Romualdez street}

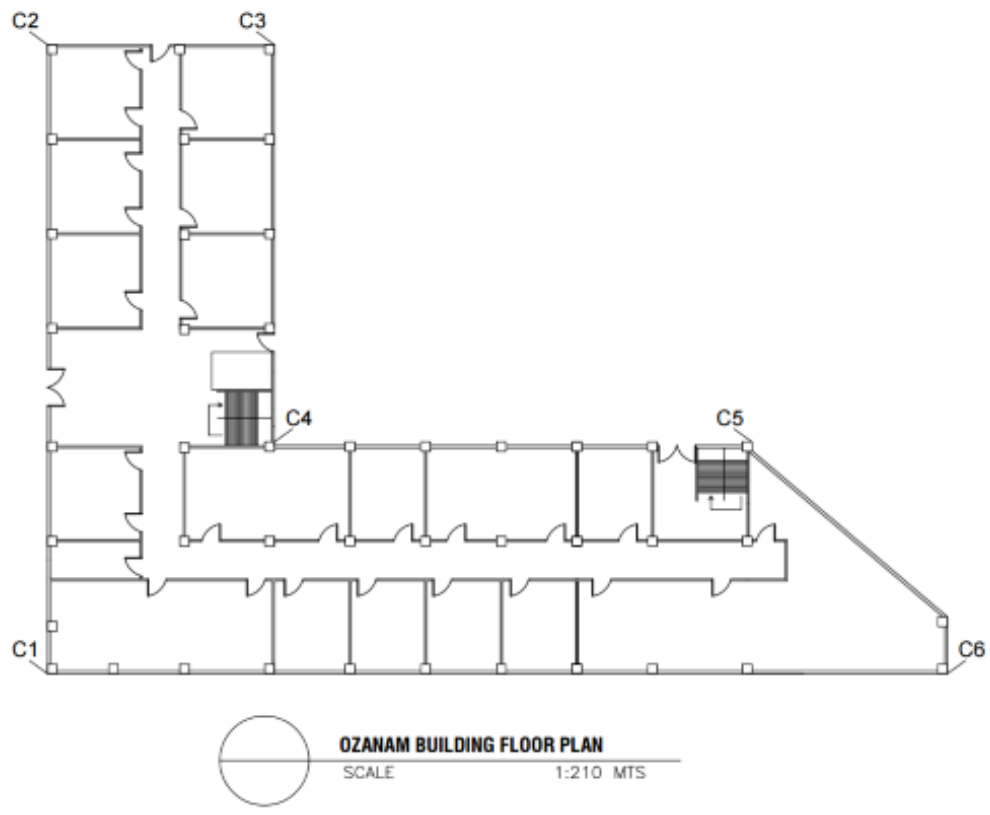

Figure 6. Columniation of the Ozanam Building

A total number of six (6) columns was considered to represent the ground floor area within the perimeter of Ozanam building as shown in Figure 6. The data obtained from the total station was able to yield the perpendicular distances of the columns with respect to the center line of the road in Romualdez Street. The setback between the property line of the Adamson University and the Ozanam 
Building is found to be $3.80 \mathrm{~m}$. The road width of the Romualdez Street is found to be 10 meters as shown in Figure 7. In addition to this, the sidewalk width along the Romualdez Street near the Ozanam Building has a width of $2.70 \mathrm{~m}$.

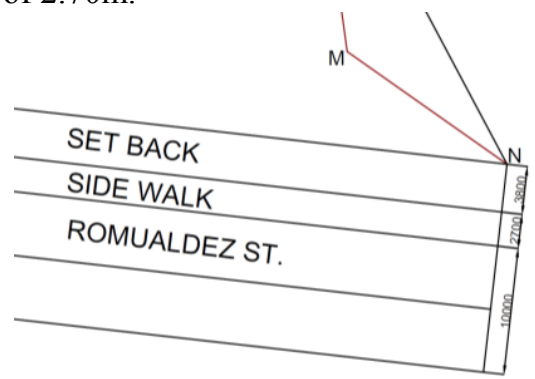

Figure 7. Widths of Setback, Sidewalk and the Romualdez Street

Table 2. Perpendicular distances of columns from the centerline of the road in Romualdez Street

\begin{tabular}{|c|c|}
\hline Column Number & Distance $(\mathrm{m})$ \\
\hline 1 & 11.50 \\
\hline 2 & 60.80 \\
\hline 3 & 56.10 \\
\hline 4 & 30.05 \\
\hline 5 & 31.07 \\
\hline 6 & 11.50 \\
\hline
\end{tabular}

The perpendicular distances of the column of Ozanam Building as shown in Table 2 was obtained by adding the computed departure using the total station, the setback, side walk, and half of the road width of the Romualdez Street.

\subsection{Peak particle velocity $(\mathrm{mm} / \mathrm{s})$ of the columns of the Ozanam building}

In order to predict the damage response of structures due to construction vibrations, it is desirable to perform a dynamic mathematical analysis of the structure. However, due to the numerous structural and environmental variables involved, even approximate analyses are difficult and expensive. Such analyses can seldom be accomplished within the scope of normal projects. Older structures are especially difficult to model dynamically because the building components are typically in varying states of deterioration, and previous settlements and movements in the structure often have redistributed the loads and stresses into unknown patterns.

When historic or landmark designated buildings are involved the cultural, social, economic, political and architectural importance of such buildings must also be considered in setting vibration limits. The possibility of damaging a unique historic building must be weighed against the increased cost of construction operations when low maximum permissible vibration limits are specified. As such, the selection of the proper vibration criterion for a historic structure becomes an economic decision as well as a technical one.

In this study, researchers considered only the first floor of the Ozanam building because vibrations originates directly on the ground floor and it propagates throughout the building.

Table 3. Summary of the Peak Particle Velocity $(\mathrm{mm} / \mathrm{s})$ of the Columns in Ozanam Building

\begin{tabular}{|c|c|c|}
\hline $\begin{array}{c}\text { Column } \\
\text { Number }\end{array}$ & $\begin{array}{c}\text { Peak Particle } \\
\text { Velocity }(\mathrm{mm} / \mathrm{s})\end{array}$ & Remarks \\
\hline 1 & 8.6 & Threshold for risk of architectural damage \\
\hline 2 & 1.8 & Unlikely to cause damage of any type \\
\hline 3 & 1.8 & Unlikely to cause damage of any type \\
\hline
\end{tabular}




\begin{tabular}{|c|c|c|}
\hline 4 & 2.0 & Effects ancient and historical monuments \\
\hline 5 & 3.1 & Virtually no risk of architectural damage to normal buildings \\
\hline 6 & 7.8 & Threshold for risk of architectural damage \\
\hline
\end{tabular}

The Lutron Vibration Meter with a model number VB-801HA was used to obtain the required peak particle velocities of each column in Ozanam Building. The following data as shown in Table 3 was obtained during experimentation:

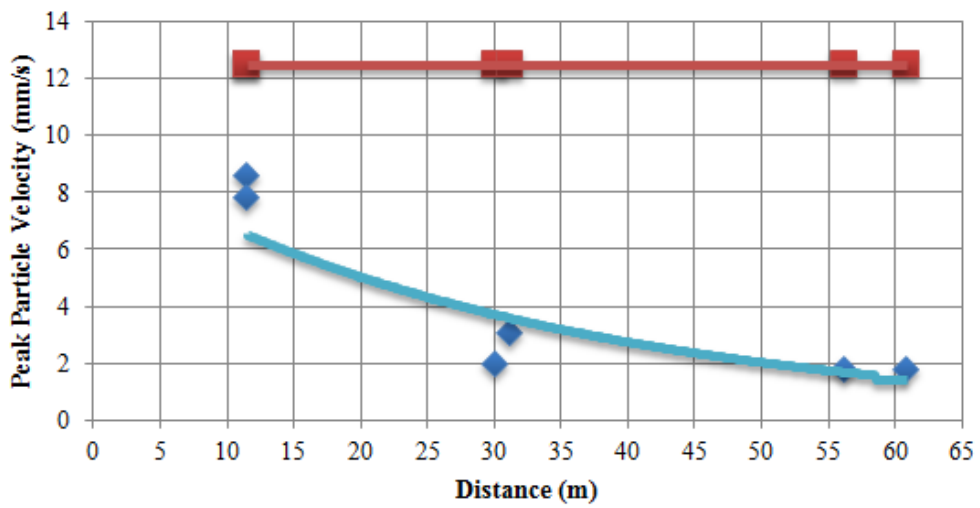

Figure 8. The relationship of peak particle velocity and distance of the columns from the centerline of the road in Romualdez Street.

As shown in Figure 8, the maximum peak particle velocity can be found on Column 1 with a value of $8.6 \mathrm{~mm} / \mathrm{s}$ approximately $11.50 \mathrm{~m}$ from the centerline of the road in Romualdez Street. This signifies that even though the Ozanam Building is exposed to such kinds of vibrations, it is still safe from any possible structural damages because according to the Traffic and Road Research Laboratory (U.K.), the minimum allowable peak particle velocity of older properties is at 12.5 millimetres per second.

\subsection{Visible cracks on the building that is due to vibrations induced by traffic at Romualdez street}

Upon close inspection of the Ozanam Building, there were no visible damages on the building that is due to vibrations induced by traffic at Romualdez Streeet in the interior. However, in the exterior or façade of the building, there are visible damages that might be caused by traffic-induced vibrations as shown in Figure 9 and 10.

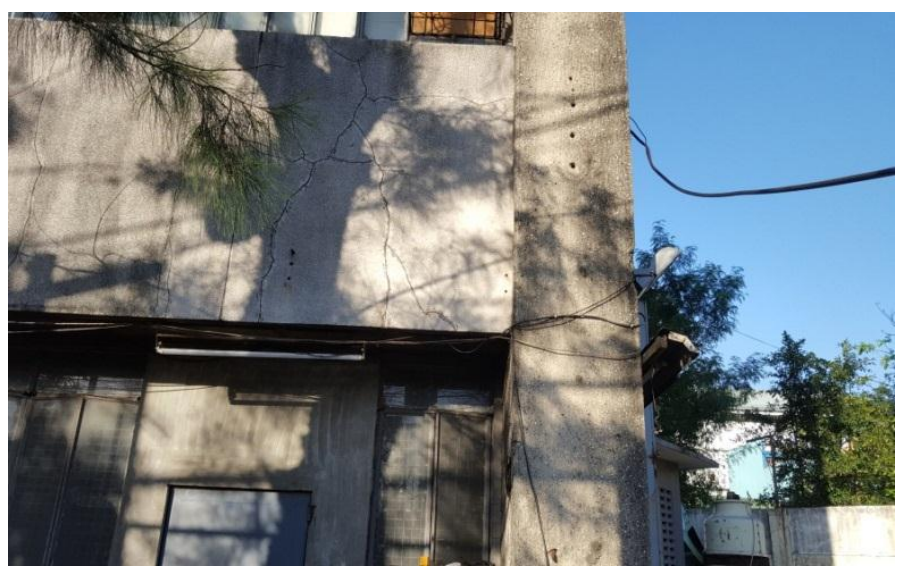

Figure 9. Cracks near the Column 6 of Ozanam Building 
In relation with the study Jakubczyk-Galczynska and Jankowski [10], when it comes to the effects of traffic-induced vibrations, they may be and small and imperceptible; however, they may as well become the reason of a major malfunction or even lead to collapse of a structure. The most visible effects of traffics are chaps and scratches on the plaster covering of the building, falling of paint, and plaster, crack on the elements of the structure or even building malfunction and collapses.

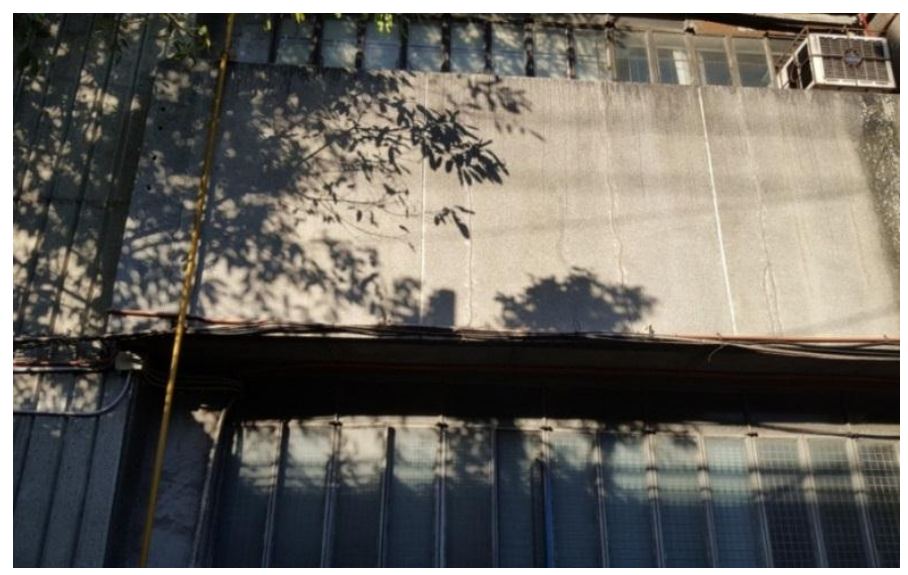

Figure 10. Cracks on the façade of the Ozanam Building

Another study by Tomazevic [11] states the traffic vibrations did not cause visible damage to the walls. They caused propagation of damage (cracks) in the case where the walls have been previously damaged. Traffic-induced vibrations caused invisible changes of the walls' structure, such as microscopic crushing of mortar and consequent softening and disintegration of masonry. These changes resulted into the measured changes in dynamic properties of the walls (natural vibration frequencies) as well as in measure changes in compressive and lateral strains under the same loading conditions.

\section{Conclusion and recommendation}

\subsection{Conclusion}

Based on careful observation and evaluation of the results obtained from the actual field-testing using vibration meter and total station, the researchers concluded the following:

- The peak hour in which vehicles that cause traffic-induced vibrations pass through the Romualdez Street was found to be at 11:00 AM to 12:00 NN with a Peak Hour Factor of 0.96 .

- The researchers found out that the peak particle velocity due to traffic-induced vibrations in Ozanam Building of Adamson University was 8.6 millimetre per second in Column 1 approximately $11.50 \mathrm{~m}$ from the centerline of the road in Romualdez Street. This implies that the building is safe since the maximum threshold value is $12.5 \mathrm{~mm} / \mathrm{s}$. Thus, vibration due to traffic has no significant effect that can cause structural damage to the building.

- As for the damages due to traffic-induced vibrations, there has been a lot of cracks that can be seen in the facade of Ozanam Building along the Romualdez Street. This can be seen on the plaster walls of the Ozanam Building around the Second Floor.

\subsection{Recommendation}

The researchers recommend the future prospects who want to undergo related studies on trafficinduced vibrations to consider the following: 
- The vibration meter used in this study has a frequency range of $10 \mathrm{~Hz}$. This means that the meter is reading with a reads the peak particle velocity every one-tenth of a second. The researchers recommend using a more sophisticated vibration meter. To be specific, it is recommended using the Lutron Vibration Meter Model No. VB-8212, which is a portable type of a vibration meter like the one used in this study, but more sophisticated because of the larger sensor.

- For the Ozanam Building of Adamson University, the Adamson University - Physical Facilities Office (AdU-PFO) should consider retrofitting of the columns with special focus on those who are near the Romualdez Street. Good design is important, but even the best design is useless if not implemented properly. For this reason, it is advisable during the entire design and retrofitting process to monitor the myriad details that may affect vibration by careful review of relevant design, construction and shop drawings, and by repeated site inspection in the course of retrofitting.

- As for the visible damages as seen in the façade of the Romualdez Street, the AdU-PFO should take in regards using a Pressurize Concrete Epoxy Injector seal the cracks. This is for consideration because the researchers do not know if the cracks are traversing the cross section of the plaster walls. If so, the researchers recommend removing and replacing new plaster walls on the façade of the Ozanam Building facing the Romualdez Street.

- Ideally, vibration measurements should also be performed after the facility has been retrofitted so that conformance with vibration specification can be verified and any residual problems can be identified and resolved. With this in mind, the researchers recommend conducting another evaluation of the traffic-induced vibrations after retrofitting of columns and sealing/replacing of cracked walls to verify if the actions taken by the Physical Facilities Office of Adamson University minimized the vibrations to an acceptable level.

\section{References}

1. J.J. Hajek, C.T. Blaney and D.K. Hein, Mitigation of highway traffic-induced vibration, In Annual Conference of the Transportation Association of Canada Charlottetown, Prince Edward Island, Session on Quiet Pavements: Reducing Noise and Vibration (2006)

2. O. Hunaidi, Traffic Vibrations in Buildings, Construction Technology Update No. 39, Institute of Research in Construction (1985)

3. H.R. Nicholls, C.F. Johnson, W.L. Duvall, USBM, Blasting Vibrations and Their Effects on Structures

4. O. Hunaidi and M. Tremblay, Canadian Journal of Civil Engineering, 24(5), 736-753 (1997)

5. A. C. Whiffin, D. R. Leonard, TRRL, A survey of Traffic-Induced Vibrations (1971)

6. M.O. Al-Hunaidi, Journal of Low Frequency Noise, Vibration and Active Control, 15(1), 25-42 (1996)

7. O. Hunaidi, J.H. Rainer and G. Pernica, Proceedings of 2nd International Symposium on Transport Noise and Vibration, 103-108 (St. Petersburg, Russia, 1994)

8. S. Mathur, A Study on Traffic Induced Vibrations (2013)

9. H. Jaswal, Analysis of Micro-Vibrations in Buildings (2007)

10. A. Jakubczyk-Galczyńska and R. Jankowski, The 9th International Conference Environmental Engineering (Vilnius, Lithuania, 2014)

11. M. Tomazevic, The Influence of Traffic-Induced Vibrations on Historic Stone Masonry Buildings, (2006) 